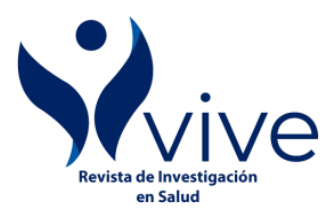

VIVE. Revista de Investigación en Salud https://doi.org/10.33996/revistavive.v4i11.94 Volumen 4 | No. 11 | Mayo - agosto 2021

http://revistavive.org

ISSN: $2664-3243$

ISSN-L: $2664-3243$

pp. $288-304$

\title{
Métodos diagnósticos de VPH para la prevención del cáncer cérvico uterino en Ecuador
}

\author{
HPV diagnostic methods for the prevention of cervical cáncer in Ecuador \\ Métodos de diagnóstico do HPV para a prevenção do câncer cervical no Equador
}

\author{
David Israel Bravo Crespo \\ dbravoc@ucacue.edu.ec \\ https://orcid.org/0000-0001-5131-4120
}

Universidad Católica de Cuenca, Ecuador

\author{
Carlos Alberto Román Collazo \\ cromanc@ucacue.edu.ec \\ https://orcid.org/0000-0002-8235-4165
}

Universidad Católica de Cuenca, Ecuador

Recibido 19 de marzo 2021 | Arbitrado y aceptado 13 de abril 2021 | Publicado en 4 de mayo 2021

\begin{abstract}
RESUMEN
El cáncer cérvico uterino (CCUes la segunda causa de muerte en mujeres entre los 35 y 64 años en Ecuador. La intervención en salud sugiere el diagnóstico temprano de la infección con el Virus del Papiloma Humano (VPH) y el estado citológico de células epiteliales cervicales. El VPH se considera la causa etiológica principal del $99 \%$ del CCU. Objetivo. Valorar el diagnóstico del CCU a partir del empleo de métodos citológicos y moleculares en mujeres de Ecuador. Métodos. Revisión sistemática sobre diagnóstico de VPH y prevención del CCU. La búsqueda abarcó artículos originales en inglés y español desde 2010-2020. Se emplearon bases de datos como Pudmed, Scielo, Elsevier, Redalyc y Scopus. Resultados. La citología como método de tamizaje primario ha disminuido la incidencia de CCU, aunque su baja sensibilidad pone límites a la eficacia. La implementación de métodos moleculares ha permitido detectar diferentes genotipos y obtener confiabilidad en los resultados, pero su accesibilidad se encuentra limitada en poblaciones con bajos recursos financieros. El poco conocimiento y la aplicación de métodos heterogéneos dificultan que se realice un diagnóstico temprano como prevención de la infección y su relación con el CCU. Conclusiones. El diagnóstico certero del CCU es una necesidad urgente en el ámbito ecuatoriano. La combinación de métodos como el PAP y los métodos moleculares de identificación del VPH pueden ser herramientas suficientes a tal efecto. La valoración adecuada de la técnica de genotipificación a emplear es relevante con la finalidad de asegurar un método de diagnóstico sensible, específico y accesible a la mujer ecuatoriana.
\end{abstract}

Palabras clave: Virus de Papiloma Humano; Cáncer de cuello uterino; Diagnóstico de VPH
DB: Docente en la Universidad Católica de Cuenca área de nivelación y admisión. Laboratorista químico y Representante técnico de las sustancias químicas sujetas a fiscalización de la Universidad Católica de Cuenca, Ecuador.

CR: Docente Universitario de Universidades de Bolivia, México, Ecuador y Cuba. Investigador en el campo de la ingeniería genética, bioquímica, educación y ética. Autor de más de 40 publicaciones indexadas. Ponente de investigaciones en más de 50 eventos científicos. Editor y árbitro de revistas científicas como MedWave y Revista Habanera de Ciencias Médicas. Universidad Católica de Cuenca, Ecuador.

\begin{abstract}
Cervical uterine cancer (CUC) is considered the second cause of death in women between the ages of 35 and 64 in Ecuador. Health intervention suggests early diagnosis of Human Papillomavirus (HPV) infection and cytological status of cervical epithelial cells. HPV is considered the main etiological cause of $99 \%$ of CCU. Objective. To assess the diagnosis of CCU from the use of cytological and molecular methods in women from Ecuador. Methods. Thematic review on HPV diagnosis and CCU prevention. The search covered original articles in English and Spanish from 2010-2020. Databases such as Pudmed, Scielo, Elsevier, Redalyc, Scopus were used. Resulted. Cytology as a primary screening method has decreased the incidence of CCU, although its low sensitivity limits efficacy. The implementation of molecular methods has made it possible to detect different genotypes and obtain reliability in the results, but their accessibility is limited in populations with low financial resources. The little knowledge and the application of heterogeneous methods makes it difficult to make an early diagnosis to prevent infection and its relationship with CCU. Conclusions. The accurate diagnosis of CCU is an urgent need in the Ecuadorian environment. The combination of methods such as PAP and molecular methods for HPV identification may be sufficient tools for this purpose. Adequate assessment of the genotyping technique to be used is relevant in order to ensure a sensitive, specific and accessible diagnostic method for Ecuadorian women.
\end{abstract}

Key word: Cervical cancer; Diagnostic HPV; Ecuador; Human Papillomavirus 
DB: Docente en la Universidad Católica de Cuenca área de nivelación y admisión Laboratoista quimicoy Representante técnico de las sustancis qúmicas Rejetas a fiscaización de la Universidad Católica de Cuenca, Ecuador. CR: Docente Universitario de Universidades de Bolivia, México, Ecuador y Cuba. Investigador en el campo de la ingeniería genética, bioquímica, educación y ética. Autor de más de 40 publicaciones indexadas. Ponente de investigaciones en más de 50 eventos científicos. Editor y árbitro de revistas científicas como MedWave y Revista Habanera de Ciencias Médicas. Universidad Católica de Cuenca, Ecuador.

\begin{abstract}
RESUMO
O câncer cervical uterino (CUC) é considerado a segunda causa de morte em mulheres entre 35 e 64 anos no Equador. A intervenção em saúde sugere o diagnóstico precoce da infecção pelo papilomavírus humano (HPV) e o estado citológico das células epiteliais cervicais. O HPV é considerado a principal causa etiológica de 99\% das UCC. Objetivo: Avaliar o diagnóstico de CCU a partir do uso de métodos citológicos e moleculares em mulheres equatorianas. Métodos. Revisão temática sobre diagnóstico de HPV e prevenção de CCU. A pesquisa cobriu artigos originais em inglês e espanhol de 2010-2020. Bancos de dados como Pudmed, Scielo, Elsevier, Redalyc, Scopus foram usados. Resultados. A citologia como método de rastreamento primário diminuiu a incidência de CCU, embora sua baixa sensibilidade limite a eficácia. A implementação de métodos moleculares tem permitido detectar diferentes genótipos e obter confiabilidade nos resultados, mas sua acessibilidade é limitada em populações com poucos recursos financeiros. $\mathrm{O}$ pouco conhecimento e a aplicação de métodos heterogêneos dificultam o diagnóstico precoce para prevenção da infecção e sua relação com o CCU. Conclusões: O diagnóstico preciso do CCU é uma necessidade urgente no meio ambiente equatoriano. A combinação de métodos como PAP e métodos moleculares para identificação do HPV podem ser ferramentas suficientes para esse fim. A avaliação adequada da técnica de genotipagem a ser utilizada é relevante para garantir um método diagnóstico sensível, específico e acessível para as mulheres equatorianas.
\end{abstract}

Palavras-chave: Papilomavírus humano; Câncer cervical; diagnóstico HPV; Câncer cervical; diagnóstico HPV

\section{INTRODUCCIÓN}

$\mathrm{E}$ 1 Virus de Papiloma Humano (VPH) es una de las infecciones de transmisión sexual más frecuente a nivel mundial. El VPH es la etiología de la aparición de verrugas benignas hasta neoplasias epiteliales oncogénicas (1). Su impacto en la salud humana es relevante siendo causante del $99 \%$ del cáncer cérvico uterino (CCU) con alta prevalencia y mortalidad. El CCU se considera la segunda causa de muerte en mujeres, entre los $35 \mathrm{y}$ 64 años a nivel mundial, resaltando el grupo entre 20 y 30 años con un $21 \%$ de prevalencia $(2,3)$.

El VPH pertenece a la familia Papillomaviridae. Es un virus pequeño con un diámetro de 60nm, icosaédrico y desnudo. La cubierta externa está formada por 72 capsómeros metaméricos y 2 proteínas estructurales (4).
El genoma viral está constituido por un ADN bicatenario entre 6800 a 8400 pb. Existen alrededor de 200 genotipos que se pueden clasificar en dependencia de su valor clínico y pueden ser detectados por técnicas moleculares, inmunohistoquímica $\mathrm{y}$ citológicas (5).

Las manifestaciones clínicas causadas por el VPH han permitido su clasificación de manera epidemiológica. (6). Los serotipos VPH de alto riesgo (AR) $(16,18,26,33,31$, $35,39,45,51,52,56,53,58,59,66,67,68$, 69, 73, 82 (subtipo MM4), 82 (subtipo IS39) se relacionan con infecciones en el espacio genital y el progreso a cáncer cervical. Los $\mathrm{VPH}$ de bajo riesgo (BR) y riesgo indeterminado(IR) $(6,11,34,40,43,42,44$, $55,54,57,61,70,71,72$, 81 у CP6108), se relacionan a lesiones benignas del espacio genital como condilomas (7). Son los principales causantes de cambios físicos y morfológicos desarrollando lesiones en el 
tejido epitelial de órganos y tejidos como el ano, pene, vulva, cuello uterino, cabeza y cuello $(8,1)$.

Se han presentado cifras alarmantes de CCU en la base de datos de la International Agency for Research of Cancer. Se resalta que de todos los agentes infecciosos que afectaron a la mayor parte de mujeres en Sudamérica en el año 2018, el virus del VPH se encuentra en primer lugar, provocando el tipo de cáncer más común en términos de nuevos casos y muertes (9).

En Ecuador, el VPH se ha erigido como un problema de salud muy importante en los últimos años. El número de nuevos casos de CCU en el año 2020 fue de 1534, correspondiendo al 9,6\% del total de cáncer en mujeres de todas las edades y un estimado de 813 personas fallecidas. La prevalencia a 5 años del CCU será de 4003 para todas las edades (10). Actualmente en Ecuador la disminución de la mortalidad por CCU es una prioridad en salud.

El sistema de salud ecuatoriano ha tratado de reducir la mortalidad y morbilidad provocada por el VPH a través de programas educativos e intervención en salud. Se ha intentado concientizar a la comunidad sobre la importancia de la aplicación de la vacuna contra el VPH y del cribado por citología como método diagnóstico. Sin embargo, se han detectado situaciones como una baja cobertura de información, educación y diagnóstico en una población de alta heterogeneidad socioeconómica, conjuntamente con elevada diversidad de métodos de diagnóstico de VPH (11).

El principal método diagnóstico empleado años atrás para la detección y control de CCU en Ecuador; es la citología cérvico-vaginal conocida como tinción de Papanicolaou (PAP). Esta técnica logró reducir la incidencia, mortalidad $\mathrm{y}$ prevalencia de neoplasias en mujeres. Sin embargo, la baja sensibilidad y especificidad que presenta puede generar resultados falsos negativos. También la baja adherencia del paciente al método diagnóstico conlleva al incremento del riesgo para la salud $(12,13)$.

Hoy en día, existen diferentes métodos diagnósticos que se aplican para la detección del VPH, con la finalidad de obtener un diagnóstico temprano y eficaz a partir de una alta sensibilidad y especificidad. Estos métodos diagnósticos se basan en fundamentos moleculares $\mathrm{y}$ bioquímicos (14).

Uno de los métodos que en la actualidad que ha contribuido de manera muy positiva al sistema de salud, en el diagnóstico temprano de infección con VPH, es la detección y tipificación genotípica. Esta ha permitido obtener mayor sensibilidad $\mathrm{y}$ especificidad mediante la detección de serotipos de alto riesgo VPHAR- 16 y 18. $(8,15)$.

Debido a la heterogeneidad de métodos y técnicas aplicadas en el diagnóstico de VPH en Ecuador, el objetivo de la investigación fue valorar el diagnóstico del CCU a partir del empleo de métodos citológicos y moleculares en mujeres de Ecuador.

\section{MÉTODO}

$\mathrm{S}$ e trata de una revisión sistemática basada en la literatura científica fue recopilada de diferentes bases de de datos como Pudmed, Scielo, Scopus, Elsevier, Redalyc y el buscador Google Académico. Se utilizó palabras clave para los diferentes métodos de diagnóstico del Virus del Papiloma humano, la sensibilidad y especificidad de las pruebas citológicas, pruebas bioquímicas y moleculares para la prevención del cáncer cérvico uterino en Ecuador. Los términos de búsqueda fueron 
verificados en los descriptores DeCS y MeSH. Las palabras claves utilizadas como estrategia de búsqueda en este estudio fueron: Virus de Papiloma Humano, Cáncer de cuello uterino, Ecuador, Diagnóstico de VPH y en inglés fueron Human Papillomavirus and HPV Diagnosis, Ecuador, Cervical cáncer. Mediante la utilización de operadores booleanos "AND, OR, NOT se conectaron de forma lógica para restringir la búsqueda de información. La estrategia de búsqueda se limitó los artículos a texto completo en humanos, idioma inglés o español durante el período 2010-2020. Los artículos fueron resumidos mediante fichas bibliográficas con los siguientes criterios: título, objetivos, palabras clave, método, análisis y conclusiones.

\section{Criterios de inclusión y exclusión}

Se incluyeron estudios originales realizados en Ecuador que hacían referencia a los métodos diagnósticos de infección con el VPH en seres humanos que denotaron la sensibilidad y especificidad del método diagnóstico.

Se excluyeron revisiones sistemáticas y artículos de opinión en cualquier otro idioma que no sea español e inglés.

\section{Extracción y análisis de datos}

Se utilizó el gestor bibliográfico Zotero, para almacenar la información y elaborar las fichas bibliográficas. Para la presentación de los resultados, se elaboraron tablas de resumen de los datos encontrados.

\section{DESARROLLO Y DISCUSIÓN}

$\mathrm{L}$ a infección por VPH puede diagnosticarse mediante exámenes citológicos o histopatológicos sugestivos de cambios morfológicos o directamente mediante pruebas moleculares. También se utilizan pruebas serológicas basadas en pruebas de anticuerpos circulantes y respuestas inmunitarias a nivel celular inducidas por infecciones virales (16).

El diagnóstico y tratamiento temprano del CCU implica un cribado de mujeres asintomáticas en edad de riesgo y su posterior seguimiento. Sin embargo, los programas de prevención en América Latina y el Caribe no han sido de gran impacto en la reducción de las ITS y la de nuevos casos de CCU. La tabla 1 ilustra el comportamiento de CCU en América Latina en el año $2020(17,18)$ :

Tabla 1. Incidencia, prevalencia y mortalidad de cáncer de cuello uterino en mujeres mayores a 35 años en Sudamérica, año 2020.

\begin{tabular}{llll}
\hline PAÍS & INCIDENCIA & PREVALENCIA & MORTALIDAD \\
\hline Brasil & 15602 & 41749 & 8409 \\
Colombia & 4128 & 11014 & 2345 \\
Argentina & 3893 & 11434 & 2327 \\
Perú & 3809 & 10141 & 2191 \\
Venezuela & 3315 & 8485 & 1975 \\
Bolivia & 1699 & 4292 & 972 \\
Ecuador & 1388 & 3644 & 784 \\
Chile & 1267 & 3696 & 755 \\
Paraguay & 944 & 2404 & 587 \\
Uruguay & 234 & 659 & 150 \\
\hline
\end{tabular}


Se estima que entre el año 2020 y 2040 la aparición de casos nuevos de CCU en mujeres de 35-85 años presente un aumento del $51 \%$ (26.276 casos). La mortalidad ascenderá a la impresionante cifra de 47.232 fallecidos (19).

El tamizaje del CCU en países de América Latina utiliza diferentes métodos. Algunos de ellos son el Cotest (prueba molecular de VPH más citología) en 53,5\%, seguida de la citología (40\%). La prueba molecular de VPH fue poco usada $(71,6 \%)$ como tamizaje primario. Los dos principales problemas identificados por el personal de salud en la estrategia de tamizaje fueron una cobertura insuficiente $(32,3 \%)$ y falta de profesionales capacitados $(27,1 \%)$. La combinación de la citología con la prueba molecular del VPH puede presentar una sensibilidad de $100 \%$ y especificidad de 93\%, la diferencia de costos permite que la citología siga siendo el principal método diagnostico en países con escasos recursos (20).

La incidencia de CCU es mayor en países de bajo recursos con un aumento de 16 casos de cáncer ocasionados por VPH por cada 100.000 habitantes al año. La incidencia cambia en varios países debido grado de desarrollo y nivel socioeconóminco. Los países desarrollados presentan un aumento de 6,9\% de casos, en cambio los países en vías de desarrollo y subdesarrollados alcanzan el $9.2 \%$ de casos. La incidencia de CCU va creciendo a medida que disminuye los ingresos en los países convirtiéndose en un factor de riesgo para las mujeres de todo el mundo. El factor principal asociado es el diagnóstico temprano de la enfermedad y su tratamiento oportuno (19).

En Sudamérica la cobertura de diagnóstico no alcanza a todas las mujeres de las distintas regiones geográficas por ausencia de programas en salud pública.
El acceso a programas de cribado pudiese disminuir considerablemente hasta el 75\% de los casos de CCU. La mortalidad en cada región es muy elevada. El mayor porcentaje de las defunciones anuales por cáncer de cuello uterino ocurren en los países: Brasil, México, Colombia, Perú, Venezuela y Argentina (21).

La tasa de mortalidad se triplica en América Latina y el Caribe siendo superior a las de América del Norte (22). Este aumento es debido la falta de conocimiento y falta de recursos económicos, lo que genera un mayor riesgo en las mujeres que habitan países menos desarrollados en comparación a las mujeres con mayores posibilidades $\mathrm{y}$ accesibilidad. (23).

En Ecuador, se observaron tasas más altas de CCU en la población de bajos recursos siendo más notable y en las mujeres de las zonas rurales, relacionado a los problemas en la calidad del diagnóstico y a las dificultades para acceder a programas de tamizaje (24). Un programa eficaz de prevención y control debe tener buena cobertura, calidad de tamizaje y detección temprana, así como la disponibilidad de un diagnóstico y tratamiento. Se requiere además servicios de orientación y sistemas de información, para mejorar la calidad de la atención y una gestión eficaz de pacientes $y$ programas (25).

\section{EL PAP como método diagnóstico en la prevención del CCU}

La introducción de la citología cervicouterina como método diagnóstico es atribuida al Dr. George Papanicolaou. Esta técnica fue avalada por la American Cáncer Society al considerarla un apoyo eficaz al diagnóstico de CCU. (26). La técnica tiene el propósito de descubrir anomalías morfológicas de las células que 
provienen de la descamación de las superficies epiteliales, de líquidos corporales o se obtienen mediante la aspiración con aguja (27). Aunque el método tiene más de 50 años, es considerado como uno de los métodos diagnóstico más útil y rentable para la detección del CCU. Sin embargo, la confiabilidad no es adecuada, influida por una deficiente toma de muestra e interpretación histoquímica (28). Una alternativa del método es la inspección visual del cuello uterino mediante la aplicación de ácido acético 5\% (IVAA) permitiendo detectar lesiones cervicales precancerosas. Su especificidad es muy baja (5,8\%) representando una alta tasa de falsos positivos. Esto tiene implicaciones con un riesgo de sobretratamiento, aunque permite detectar verrugas $\mathrm{y}$ otros crecimientos anormales que aparecen como manchas blancas en la piel o mucosas (29).

Los exámenes citológicos con células epiteliales escamosas anormales arrojan diagnósticos que emplean diversos sistemas de clasificación. Estos se pueden agrupar como: (ASC-US-células escamosas atípicas de significado indeterminado); (ASC-H-células escamosas atípicas que no excluyen una lesión intraepitelial de alto grado); (LIEBG-lesión intraepitelial escamosa de bajo grado), (NIC I-displasia leve o neoplasia intraepitelial cervical); (LIEAG-lesión intraepitelial escamosa de alto grado),(NIC II-displasia moderada ), (NIC III-displasia severa) o (CIS-carcinoma in situ) y el carcinoma de células escamosas. Es necesario resaltar que se usan dos nomenclaturas diferentes según el sistema de clasificación empleado (30).

Las limitaciones mediante el diagnóstico por PAP están en la obtención de una muestra de alta calidad con fijación y tinción apropiada, factores relacionados con extendido hemático, células inflamatorias y detritus celulares (32). La técnica de citología convencional, no capta la totalidad de la muestra debido a que se desecha cerca del $80 \%$ de la misma, además de no lograr una fijación completa debido a extendidos gruesos que ocasionan una coloración defectuosa, imposibilitando la observación de las células y originando un deterioro en la calidad diagnóstica con la predisposición de generar falsos negativos (33).

Un adecuado entrenamiento del personal y fijación adecuada de la muestra en el tiempo requerido son alternativas para mejorar el diagnóstico. Una vez en el laboratorio, el resultado de la citología depende enteramente del ojo entrenado del cito-tecnólogo, por lo que es fundamental tener sistemas de control de calidad internos y externos (34).

El uso de la citología en Latinoamérica no ha sido de gran impacto en la reducción de la mortalidad comparable a la registrada en los países desarrollados (35). En América Latina, aunque existe la disponibilidad del PAP, alrededor de 32 000 mujeres mueren cada año por cáncer de cuello uterino. Se ha demostrado que aún con adecuado control de calidad, la citología convencional tiene una sensibilidad baja. El éxito de algunos de estos programas no reside en la sensibilidad de la prueba, sino en la repetición constante de la misma y en el seguimiento sistematizado de mujeres con anormalidades citológicas que aseguran el diagnóstico y el tratamiento definitivo de lesiones detectadas (36).

La Sociedad Americana de Cáncer recomienda realizar una prueba PAP anual a todas las mujeres con vida sexual activa y menores de 30 años. Después de los 30 años una vez que se documenten 3 exámenes negativos consecutivos puede 
realizarse cada 2 o 3 años. La sensibilidad y especificidad de la técnica permite identificar a las personas afectadas de la enfermedad cáncer o precáncer. Si la técnica tiene una mayor sensibilidad, menor será el número de mujeres enfermas identificadas como sanas por error (resultado negativo falso). Si la técnica tiene una mayor especificidad, menor será el número de mujeres con úteros sanos identificadas como enfermas por error (resultado positivo falso).

El valor promedio de sensibilidad del PAP es de $61,3 \%$ con una dispersión considerable (18,6-94\%), lo que confirma la elevada subjetividad de este método. Además, se ilustra la necesidad de un control estricto de calidad y la repetición frecuente. La sensibilidad del método aumenta con la edad de las mujeres (79,3\% después de los 50 años; 55,4\% entre los 35-49 años y 48,7\% por debajo de los 35 años) (37).

El análisis histopatológico presenta ciertas limitaciones que afectan su precisión. Esto hace que el diagnóstico sea subjetivo y susceptible a la observación y grado de entrenamiento del patólogo, disminuyendo la sensibilidad y especificidad. Esta situación hace ha generado la necesidad de implementar métodos alternativos que brinden un pronóstico temprano y confiable (31).

\section{Diagnóstico molecular de infección con HPV}

Los avances científicos han permitido reducir la incidencia de CCU en varios países de Europa y Norte América mediante la aplicación de los diferentes métodos moleculares. Estos permiten detectar la presencia de VPH mediante la amplificación directa del ADN viral. Se puede identificar diferentes serotipos de VPH considerados VPH AR - en las células del cuello del útero; Presentan una alta sensibilidad (95\%) con un alto valor predictivo negativo que separa el intervalo del tamizaje. También favorece la identificación de lesiones mejorando la sensibilidad del PAP. Su uso ha provocado una disminución considerable en la incidencia y prevalencia del cáncer cérvico uterino en los países desarrollados (15).

El diagnóstico por el test de VPH brinda mayor sensibilidad que la citología en la detección de CIN2+ con un valor predictivo negativo (VPN) cercano al $100 \%$. Varios estudios realizados revelan que el VPN permanecerá elevado con el pasar del tiempo, hasta seis años. Se comparó el tamizaje del test de VPH con citología observando que la incidencia acumulada de cáncer cervical disminuyó 5,5 años después de la aplicación del test de VPH negativo. Para la citología negativa el valor fue de 3,5 años lo que demuestra mayor seguridad para el tamizaje con test de VPH que con citología (38).

El método molecular tiene una sensibilidad alta (aproximadamente 90\%) con un intervalo de confianza (84,9-100\%) independiente de la edad. La especificidad del método es variable según la edad de la paciente y se vincula a la presencia de infecciones transitorias en población adulta joven (39).

La muestra para el tamizaje se obtiene de las células epiteliales, insertando de manera suave y profunda en la vagina un cepillo pequeño. Luego se coloca la muestra obtenida en un envase pequeño que contiene una solución conservadora. La toma de muestra directa puede ser autogestionada; mediante el cepillo y el envase especial con la solución conservadora previa revisión de las instrucciones y procedimiento. Con la técnica de toma directa por parte de la mujer puede generar un costo más bajo para el servicio de salud y una mayor comodidad a las mujeres (40). 


\section{Técnicas moleculares para moleculares empleadas en el diagnóstico detección de VPH en Ecuador de la infección con VPH en mujeres en \\ Actualmente en Ecuador existe una edad reproductiva. La Tabla 2 resume las elevada heterogeneidad de técnicas características principales de cada una.}

Tabla 2. Técnicas moleculares utilizadas en Ecuador para el diagnóstico de infección con HPV en mujeres en edad reproductiva.

\begin{tabular}{|c|c|c|c|}
\hline Producto & Descripcion & $\begin{array}{c}\text { Sensibilidad } \\
\text { /Especificidad }\end{array}$ & Ventajas y Limitaciones \\
\hline Cobas 4800 & 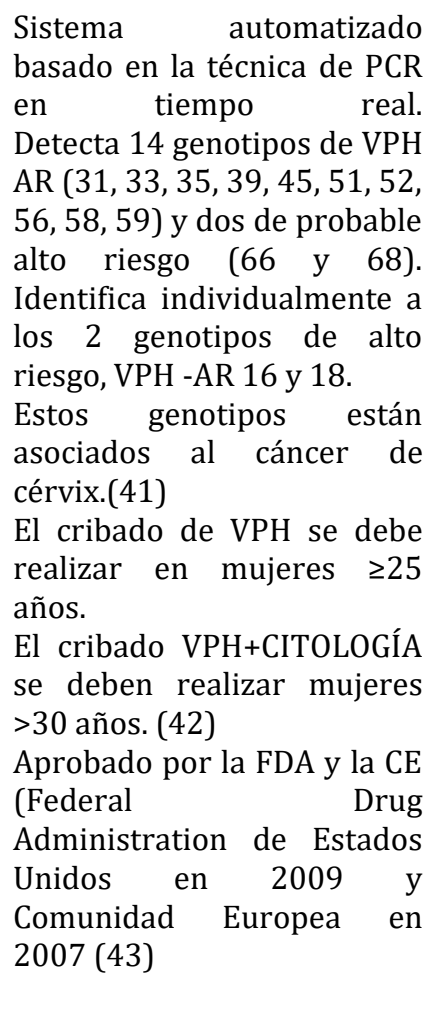 & $\begin{array}{l}\text { Sensibilidad: } 90 \% \\
\text { IC del 95\%: } 82,4 \text { a } 97,6 \\
\text { Especificidad: } 94,6 \% \\
\text { IC del 95\%: } 93,0 \text { a } 96,2 \\
\text { para CIN2. (44) }\end{array}$ & $\begin{array}{l}\text { Ventaja: Esta técnica permite } \\
\text { obtener } 3 \text { resultados en una } \\
\text { sola prueba. (41) } \\
\text { Disminuye el tiempo de } \\
\text { procesamiento de las muestras. } \\
\text { No genera reacciones cruzadas } \\
\text { con los genotipos de HPV de } \\
\text { bajo riesgo. } \\
\text { Mayor sensibilidad en pacientes } \\
\text { con riesgo de desarrollar una } \\
\text { neoplasia cervical de alto } \\
\text { grado.(45) } \\
\text { Limitaciones: } \\
\text { Realiza la amplificación de solo } \\
\text { un fragmento específico del gen } \\
\text { L1 lo que puede incrementar el } \\
\text { número de resultados con falsos } \\
\text { negativos. Respecto de la } \\
\text { identificación con los genes E6 y } \\
\text { E7, esto en cuanto a la detección } \\
\text { del virus se refiere. (46) } \\
\text { Carece de un sistema de } \\
\text { verificación de insumos para el } \\
\text { procesamiento de las muestras } \\
\text { disminuyendo la calidad del } \\
\text { proceso. }\end{array}$ \\
\hline $\begin{array}{l}\text { Captura } \\
\text { Híbrida II VPH } \\
\text { (AR): }\end{array}$ & $\begin{array}{l}\text { Es un método } \\
\text { semicuantitativo, basado en } \\
\text { la hibridación del ADN de } \\
\text { HPV mediante sondas de } \\
\text { ARN, usando anticuerpos } \\
\text { monoclonales específicos } \\
\text { que se revelan por } \\
\text { quimioluminiscencia } \\
\text { Detecta cinco genotipos de } \\
\text { VPH-BR (6,11,42,43,44) y } \\
\text { trece de VPH-AR } \\
\text { (13,16,18,31,33,35,39,45,51, } \\
52,56,58,59 \text { y 68) } \\
\text { - El cribado debe incluir VPH } \\
\text { y CITOLOGÍA para más de } 30 \\
\text { años. (47) }\end{array}$ & $\begin{array}{l}\text { Sensibilidad a: } 94.8 \% \\
\text { Especificidad: } 67.3 \% \text { (48), } \\
\text { (39) } \\
\text { Asociada con lesión NIC2/ } \\
\text { NIC3+. (49) }\end{array}$ & $\begin{array}{l}\text { Ventajas: El uso de la citología } \\
\text { normal con un test de ADN, } \\
\text { permite una mayor sensibilidad, } \\
\text { aumentando la detección de } \\
\text { cáncer en un } 60-70 \% \text {. } \\
\text { Limitaciones: } \\
\text { Puede } \\
\text { contaminación por fallas en el } \\
\text { lavador empleado. } \\
\text { - Reporte de falsos negativos } \\
\text { por el escaso número de } \\
\text { células con copias virales, limita } \\
\text { la detección } \\
\text { (50). }\end{array}$ \\
\hline
\end{tabular}




\begin{tabular}{|c|c|c|c|}
\hline Producto & Descripcion & $\begin{array}{l}\text { Sensibilidad } \\
\text { /Especificidad }\end{array}$ & Ventajas y Limitaciones \\
\hline
\end{tabular}

La no identificación individual de genotipos virales de VPHAR limita el uso de la técnica para seguimiento rutinario en caso de infecciones persistentes o estudios de prevalencia y genotipificación viral.

No excluye los diferentes genotipos de HPV encontrados en una infección múltiple. (51)

\section{Anyplex II \\ HPV28 de tiempo real}

Xpert HPV
Diagnóstico in vitro que detecta 19 genotipos de VPH-AR $(16,18,26,31,33$, $35,39,45,51,52,53,56$, $58,59,66,68,69,73,82) \mathrm{y}$ 9 VPH-BR $(6,11,40,42,43$, $44,54,61,70) .(52)$

Aprobado por CE (53)
Sensibilidad: $98,3 \%$

IC del 95\%:

99,8) para CIN2

Especificidad: 93,6\%

IC del 95\%: $(89,8-96,1)$

para CIN2. (53)

Ventajas: Realiza la genotipificación de múltiples cepas en una sola reacción y su cuantificación relativa, siendo adecuada para la implementación en laboratorios de baja, mediana o elevada carga de trabajo. (54)

Limitaciones: La sensibilidad disminuye al incrementar tiempo de almacenamiento o congelación descongelación de la muestra

Una adecuada toma de muestra, transporte, almacenamiento y ejecución del procedimiento brinda alta confiabilidad en los resultados. (53)

Limitaciones: El procesamiento de las muestras se pueden procesar de una en una. (49)

Sensibilidad: $91,55 \%$

Especificidad: 41,3\% detectar ADN de 14 tipos de VPH: 16,18/45, $31 / 33 / 35 / 52 / 58,51 / 59$, 39/56/66/68. (49)

Es un método cualitativo in vitro, se basa en la amplificación del ADN mediante reacción en cadena de la polimerasa (PCR) e hibridación en línea reversa

Con capacidad para detectar ADN del VPH de 37 tipos de VPH anogenitales.(58) Aprobado por CE. (53)
Sensibilidad: $93 \%$

Especificidad: 84\%

Para CIN2. (53)
Ventajas: Tiene control interno, la ejecución de esta técnica en estudios epidemiológicos favorece la información clínica el cual permite conocer el tipo específico de VPH y las infecciones múltiples, posibilitando realizar un seguimiento particular de la permanencia de la infección 


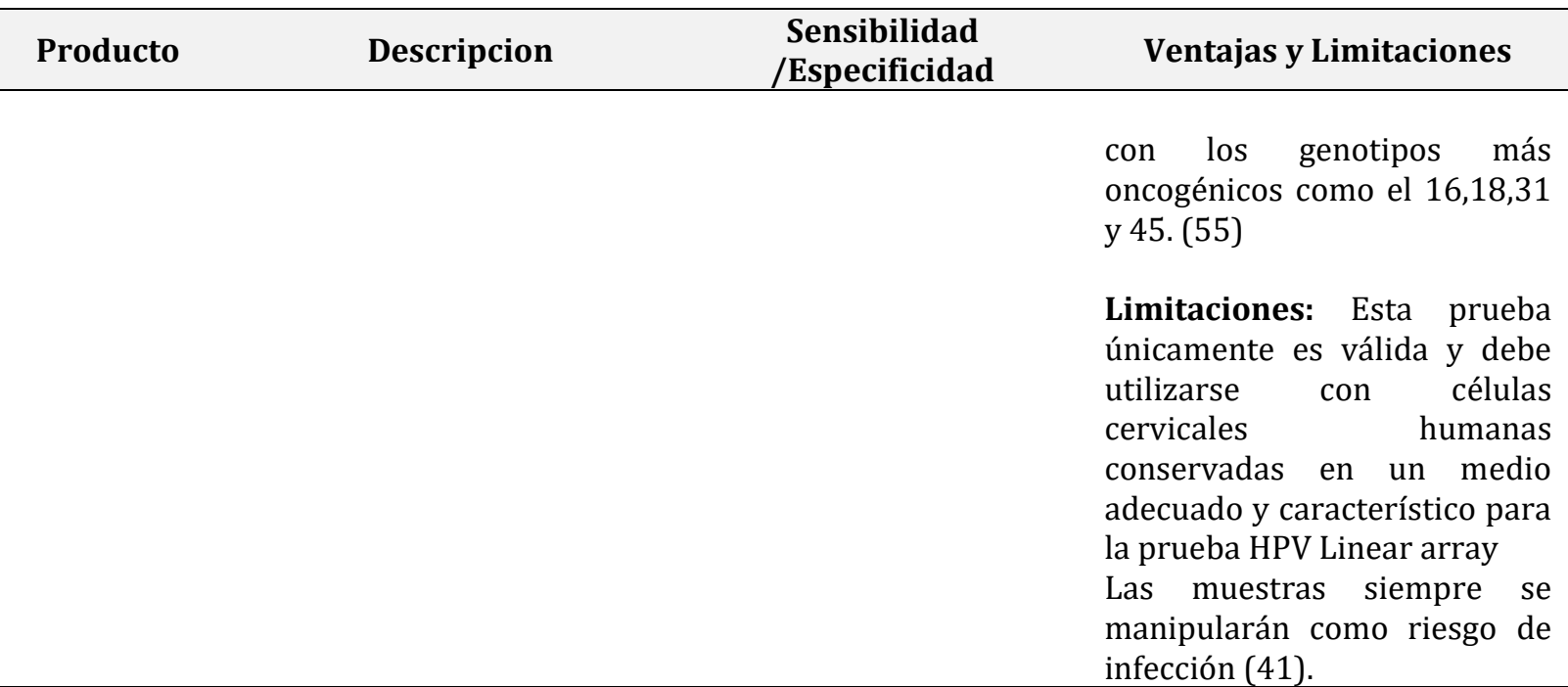

La implementación de la citológica cervicouterina durante décadas como método diagnóstico primario ha permitido disminuir la prevalencia de CCU en toda Latinoamérica. Sin embargo, actualmente no se perciben beneficios de su uso en mitigar las muertes por CCU.

El avance tecnológico ha permitido desarrollar nuevos métodos de diagnóstico molecular, entre ellos las técnicas moleculares que han tenido mucho éxito principalmente en países desarrollados. Estos permiten un tamizaje primario, con una alta sensibilidad y especificidad generando confiabilidad en los resultados obtenidos mediante el diagnóstico molecular.

En Ecuador se ha priorizado para tamizaje primario la citología PAP en el diagnóstico de CCU. Su bajo costo y accesibilidad hacen de la prueba una alternativa importante según la situación socioeconómica del país. Sin embargo, algunos criterios científicos como sensibilidad, especificidad y valor pronóstico deben ser considerados en la decisión.

El uso del diagnóstico molecular del VPH es ventajoso en el ámbito de la salud por la alta sensibilidad y especificidad. Sin embargo, la heterogeneidad de técnicas disponibles en el mercado hace que el tecnólogo deba seleccionar de manera adecuada la técnica de uso. Reflexionar sobre las ventajas y desventajas de las técnicas es relevante para su correcto uso.

Un aspecto a tener en cuenta es la edad de la paciente. En mujeres menores de 30 años de edad, la identificación de VPH no es señal de CCU. La mayor parte de las infecciones con VPH desaparecerán espontáneamente antes de los 30 años de edad. El tamizaje también puede verse limitado por la necesidad de espacios, equipos costosos y técnicos capacitados para el desarrollo del tamizaje (56).

Al considerar el diagnóstico, es relevante la combinación del PAP y la genotipificación pues unificaría la toma de muestra biológica. Esta consideración es un factor importante dentro del tamizaje porque favorecería la adherencia al diagnóstico. El proceso de diagnóstico debe asegurar la comodidad de la mujer al obtener la muestra por un profesional del mismo género y que las molestias causadas por la toma de muestra sean minimizadas. 
Una de las ventajas de estos métodos es la combinación con los estudios citológicos lo que permite mejorar el valor predictivo negativo del PAP, permitiendo la ampliación en los intervalos de periodicidad del tamizaje y la disminución en los costos de programas de salud (57).

La implementación del método molecular a nivel local se ha visto afectada. En Ecuador y varios países de Latinoamérica la accesibilidad de la población al diagnóstico es ínfima. Los elevados costos de importación de kits comerciales y su traslado al valor de las pruebas diagnósticas en el orden privado hacen que su uso sea de último recurso. Tampoco existe un programa de salud pública que incluya los métodos moleculares como parte del tamizaje del CCU. También la cobertura por área geográfica es limitada, situación relacionada a cuestiones de infraestructura, tecnología, recursos humanos y características socioculturales de la mujer ecuatoriana. La implementación de los métodos diagnósticos moleculares no ha sido de gran impacto para el sistema de salud en Ecuador, limitando el uso a la población de escasos recursos económicos.

Se recomienda el uso de la citología conjuntamente con el método molecular por su alta sensibilidad y especificidad en los diferentes estadios de la infección por VPH. También se sugiere realizar un seguimiento estricto al paciente luego de su primer control, teniendo en cuenta previas lesiones diagnosticadas y mantener activos los programas de prevención de CCU en toda la población, incentivando a todas las mujeres a acudir a los controles periódicos para obtener un diagnóstico temprano y evitar el desarrollo de CCU.

\section{CONCLUSIÓN}

$\mathrm{E}$ I diagnóstico certero del CCU es una necesidad urgente en el ámbito ecuatoriano. Su implementación de manera adecuada puede minimizar las muertes y aumentar la calidad de vida de la mujer ecuatoriana. La combinación de métodos como el PAP y los métodos moleculares de identificación de infección con VPH pueden ser herramientas suficientes a tal efecto. La valoración adecuada de la técnica de genotipificación a emplear es relevante con la finalidad de asegurar un método de diagnóstico sensible y específico. Se debe implementar una política de salud en el área pública y privada de modo que garantice el acceso de la mujer ecuatoriana a los métodos moleculares de diagnóstico de VPH.

\section{REFERENCIAS BIBLIOGRÁFICAS}

1. Hernández DE. Biología del Virus del Papiloma Humano y su relación con el cáncer. Rev Venez Oncol [Internet]. [citado 21 de diciembre de 2020];29(4):295-303. Disponible en: https://www.redalyc.org/jatsRepo/3756/ 375652706012/html/index.html

2. Yenddy C, Elizabeth P-P, Fernanda V, Alex A, Carmen V-R, Alicia Z-C. Infección por VPH y su correlación clínica en población indígena de la región altoandina del Ecuador. Kasmera [Internet]. [citado 2 de marzo de 2021];46(2):152-8. Disponible en: https://www.redalyc.org/jatsRepo/3730/ 373061528006/html/index.html

3. Erazo-Luna EV, Velásquez-Lopera MM. Respuesta inmunológica al virus del papiloma humano. Dermatol Rev Mex 2019 enero-febrero;63(1):40-59 
[Internet]. 2019;20. Disponible en: https://www.medigraphic.com/pdfs/derr evmex/rmd-2019/rmd191f.pdf

4. Lissabet JFB. Aspectos generales sobre la estructura y función de las proteínas codificadas por el virus del Papiloma Humano. Rev CENIC Cienc Biológicas [Internet]. 2014 [citado 5 de mayo de 2021];45(2):108-18. Disponible en: https://www.redalyc.org/articulo.oa?id=1 81231236005

5. Sendagorta-Cudós E, Burgos-Cibrián J, Rodríguez-Iglesias M. Infecciones genitales por el virus del papiloma humano. Enfermedades Infecc Microbiol Clínica [Internet]. 1 de mayo de 2019 [citado 20 de diciembre de 2020];37(5):324-34. Disponible en: http://www.elsevier.es/esrevista-enfermedades-infecciosasmicrobiologia-clinica-28-articuloinfecciones-genitales-por-el-virusS0213005X19301223

6. Santos-López G, Márquez-Domínguez L, Reyes-Leyva J, Vallejo-Ruiz V. Aspectos generales de la estructura, la clasificación y la replicación del virus del papiloma humano. Rev Médica Inst Mex Seguro Soc [Internet]. 2015 [citado 5 de mayo de 2021];53(2):S166-71. Disponible en: https://www.redalyc.org/articulo.oa?id=4 57744942008

7. Chacón J, Mateos ML, Sanz I, Rubio MD, Baquero F. Genotipos de virus del papiloma humano más frecuentes en mujeres con citología cervicovaginal alterada utilizando técnicas de captura de híbridos y reacción en cadena de la polimerasa. Clínica E Investig En Ginecol Obstet [Internet]. 1 de mayo de 2006 [citado 18 de marzo de 2021];33(3):97101. Disponible en: http://www.elsevier.es/es-revista-clinicae-investigacion-ginecologia-obstetricia-7articulo-genotipos-virus-del-papilomahumano-13087818

8. Rivera A, De la Plata J, Montiel M, Romero C, Piedrahita P, Sánchez E, et al. Estudios sobre el virus del papiloma humano (VPH) en el Ecuador: parte I.
INSPILIP [Internet]. 2018 [citado 5 de mayo de 2021];1-22. Disponible en: https://bit.ly/2G2c4gB

9. Ferlay J, Colombet M, Soerjomataram I, Mathers C, Parkin DM, Piñeros $M$, et al. Estimating the global cancer incidence and mortality in 2018: GLOBOCAN sources and methods. Int J Cancer [Internet]. 2019 [citado 5 de mayo de 2021];144(8):1941$53 . \quad$ Disponible en: https://onlinelibrary.wiley.com/doi/abs/ 10.1002/ijc.31937

10. Sung H, Ferlay J, Siegel RL, Laversanne M, Soerjomataram I, Jemal A, et al. Global cancer statistics 2020: GLOBOCAN estimates of incidence and mortality worldwide for 36 cancers in 185 countries. CA Cancer J Clin [Internet]. [citado 5 de mayo de 2021];n/a(n/a). Disponible en: https://acsjournals.onlinelibrary.wiley.co m/doi/abs/10.3322/caac.21660

11. Cáncer cervicouterino - OPS/OMS | Organización Panamericana de la Salud [Internet]. [citado 5 de mayo de 2021]. Disponible en: https://www.paho.org/es/temas/cancercervicouterino

12. Carrión Ordoñez JI, Soto Brito Y, Pupo Antúnez M, Loja Chango R. Infección por Virus del Papiloma Humano y citología cérvico-vaginal en mujeres indígenas del Cañar, Ecuador. Bionatura [Internet]. 15 de agosto de 2019 [citado 10 de diciembre de 2020];4(3):934-8. Disponible en: https://www.revistabionatura.com/2019. 04.03.10.html

13. Amaya MP de, Moreno-Acosta $P$, Mora M. Citología convencional y en base líquida en muestra compartida de tomas cervicouterinas. Rev Repert Med Cir [Internet]. 1 de marzo de 2015 [citado 5 de mayo de 2021];24(1):41-6. Disponible en: https://revistas.fucsalud.edu.co/index.php /repertorio/article/view/652

14. Rincón R DF, Morales L LA, RincónOrozco B, Rincón R DF, Morales L LA, Rincón-Orozco B. Modern diagnostic methods for detection of Human 
Papillomavirus and cervical cancer prevention. Rev Univ Ind Santander Salud [Internet]. septiembre de 2017 [citado 20 de mayo de 2020];49(3):478-88. Disponible en: http://www.scielo.org.co/scielo.php?scrip $\mathrm{t}=\mathrm{sci} \_$abstract\&pid=S0121-

08072017000300478\&lng=en\&nrm=iso\&t lng=es

15. Bedoya C, Sánchez-Giler S, Zambrano D, Herrera A, Silva A, Kuon-Yeng C, et al. Caracterización clínica e histopatológica de la infección por Papiloma Virus humano de muestras de cérvix. Hospital Teodoro Maldonado Carbo "IESS". Rev Cienc Unemi [Internet]. 2017 [citado 5 de mayo de 2021];10(23):105-11. Disponible en: https://www.redalyc.org/articulo.oa?id=5 82661260010

16. Logroño IEN, Rea $D$, Romero $L$, Rubio J, Sañaicela J, Vallejo J, et al. TEST de virus papiloma humano como método de screening primario para el diagnóstico de neoplasias de cérvix uterino. Cienc Al Serv Salud [Internet]. 5 de diciembre de 2017 [citado 21 de diciembre de 2020];8(1):5972.

Disponible

en:

http://revistas.espoch.edu.ec/index.php/c ssn/article/view/8

17. Toro R, Reigosa A, Castro J, Contreras A, Del Villar M, González P, et al. Factores histológicos relacionados con resultados discordantes entre la biopsia y la prueba de $\mathrm{ADN}$, en el diagnóstico del virus papiloma humano (VPH). Salus [Internet]. agosto de 2016 [citado 5 de mayo de 2021];20(2):30-6. Disponible en: http://ve.scielo.org/scielo.php?script=sci_ abstract\&pid=S1316-

$71382016000200007 \& \operatorname{lng}=e s \& n r m=i s o \& t$ lng=es

18. Sung H, Ferlay J, Siegel RL, Laversanne M, Soerjomataram I, Jemal A, et al. Global cancer statistics 2020: GLOBOCAN estimates of incidence and mortality worldwide for 36 cancers in 185 countries. CA Cancer J Clin [Internet]. [citado 5 de mayo de 2021];n/a(n/a). Disponible https://acsjournals.onlinelibrary.wiley.co m/doi/abs/10.3322/caac.21660

19. Regalado JG, Rosales VQ, Leverone RB. Situación epidemioógica del cáncer cérvicouterino en el Ecuador. 2020. Rev Venez Oncol Vol 33 Núm 22021 [Internet]. 2021;33:13. Disponible en: https://www.redalyc.org/jatsRepo/3756/ 375665418004/375665418004.pdf

20. Negrin LGC. Epidemiology of cervical cancer in Latin America. ecancer 2015, 9:577 [Internet]. 8 de octubre de 2015 [citado 5 de mayo de 2021]; Disponible en: http://ecancer.org/es/journal/article/577 -epidemiology-of-cervical-cancer-in-latinamerica

21.Laberiano Fernández CD. Estado del tamizaje del cáncer de cérvix en países de América Latina desde la perspectiva de los profesionales de salud. Rev Peru Ginecol Obstet [Internet]. 3 de febrero de 2020 [citado 5 de mayo de 2021];66(1):37-40. Disponible en: http://www.spog.org.pe/web/revista/ind ex.php/RPGO/article/view/2231

22. Marañón Cardonne $T$, Mastrapa Cantillo K, Flores Barroso Y, Vaillant Lora L, Landazuri Llago S. Prevención y control del cáncer de cuello uterino. Correo Científico Méd [Internet]. marzo de 2017 [citado 16 de marzo de 2021];21(1):187$203 . \quad$ Disponible en: http://scielo.sld.cu/scielo.php?script=sci_a bstract\&pid=S1560-

$43812017000100015 \& \operatorname{lng}=e s \& n r m=i s o \& t$ lng $=\mathrm{es}$

23. Por un futuro sin cáncer del cuello uterino: por primera vez el mundo se ha comprometido a eliminar un cáncer OPS/OMS | Organización Panamericana de la Salud [Internet]. [citado 19 de marzo de 2021]. Disponible en: https://www.paho.org/es/noticias/17-112020-por-futuro-sin-cancer-cuellouterino-por-primera-vez-mundo-se-hacomprometido

24. Valdivia L IM, Aguayo G F, Pruyas A M, Snijders PJF, Corvalán R A, Ferreccio R C. Genotipos de virus papiloma humano 
(VPH) en pacientes con cáncer cervicouterino en un hospital público y una clínica privada de Santiago, Chile. Rev Chil Infectol [Internet]. febrero de 2010 [citado 18 de marzo de 2021];27(1):11-5. Disponible en: https://scielo.conicyt.cl/scielo.php?script= sci_abstract\&pid=S0716-

10182010000100001\&lng=es\&nrm=iso\&t lng=es

25. Noreña-Quiceno $C$, Tamayo-Acevedo LS, Universidad de Antioquia, Universidad de Antioquia. Cervical Cancer: Analysis of the Quality of a Program. AQUICHAN - ISSN 1657-5997 [Internet]. 1 de abril de 2010 [citado 6 de mayo de 2021];10(1):52-68. Disponible en: http://aquichan.unisabana.edu.co/index.p hp/aquichan/article/view/1606/2003

26. Lewis MJ. Análisis de la situación del cáncer cervicouterino en América Latina y el Caribe [Internet]. Washington, D.C. OPS.: Pan American Health Organization; 2004 [citado 5 de mayo de 2021]. 1-40 p. Disponible

en: https://iris.paho.org/handle/10665.2/762

27. Puerto de Amaya M, Moreno-Acosta $\mathrm{P}$, Mora M. Citología convencional y en base líquida en muestra compartida de tomas cervicouterinas. Rev Repert Med Cir [Internet]. 1 de marzo de 2015 [citado 5 de mayo de 2021];24(1):41-6. Disponible en: https://revistas.fucsalud.edu.co/index.php /repertorio/article/view/652

28. Curiel-Valdés J de J. Citología vaginal: la importancia de la zona de transformación y cómo obtener una muestra adecuada. Gac Médica México [Internet]. 2002;138(3):8. Disponible en: https://www.medigraphic.com/pdfs/gace ta/gm-2002/gm023f.pdf

29. Rosado Flores MJ, Ocon Roncal RE, Navarrete Mejía PJ, Loayza Alarico MJ. Utilidad de la citología e inspección visual con ácido acético en la detección de lesiones neoplásicas de cuello uterino Centro Médico Oncomujer 2013-2014. Lima, Perú. Horiz Méd Lima [Internet]. octubre de 2017 [citado 6 de mayo de 2021];17(4):15-8. Disponible en: http://www.scielo.org.pe/scielo.php?scrip $\mathrm{t}=$ sci_abstract\&pid=S1727-

558X2017000400003\&lng=es\&nrm=iso\&t $\operatorname{lng}=\mathrm{pt}$

30. Lau Serrano D, Millán Vega $M M$, Fajardo Tornés Y, Sánchez Alarcón C. Lesiones preinvasivas del cuello uterino. Rev Cuba Obstet Ginecol [Internet]. septiembre de 2012 [citado 2 de mayo de 2020];38(3):366-77. Disponible en: http://scielo.sld.cu/scielo.php?script=sci_a bstract\&pid=S0138-

$600 X 2012000300009 \& \operatorname{lng}=\mathrm{es} \& \mathrm{nrm}=\mathrm{iso} \& \mathrm{t}$ lng $=\mathrm{es}$

31. GARCiA A, Falcoff N, Camillo ND, Sartor $B$, Catanese $M$, Denninghoff $V$. Inmunohistoquímica de la proteína p16NK4a en biopsias y extendidos cervicovaginalesy su relación con HPV por PCR. Med B Aires 200868 428-432 [Internet]. 2008;5. Disponible en: http://www.scielo.org.ar/pdf/medba/v68 n6/v68n6a03.pdf

32. Contreras HR. Papanicolaou y citología líquida en diagnóstico de cáncer de cérvix: Hospital Civil de Maracay. 2012. Comunidad Salud [Internet]. junio de 2015 [citado 6 de mayo de 2021];13(1):12-22. Disponible en: http://ve.scielo.org/scielo.php?script=sci_ abstract\&pid=S1690-

$32932015000100003 \& \operatorname{lng}=e s \& n r m=i s o \& t$ lng=es

33. Almonte $M$, Murillo $R$, Sánchez GI, Jerónimo J, Salmerón J, Ferreccio C, et al. Nuevos paradigmas y desafíos en la prevención y control del cáncer de cuello uterino en América Latina. Salud Pública México [Internet]. diciembre de 2010 [citado 16 de marzo de 2021];52:544-59. Disponible en: https://scielosp.org/article/spm/2010.v5 2n6/544-559/es/

34. Cáncer cervicouterino - OPS/OMS | Organización Panamericana de la Salud [Internet]. [citado 19 de marzo de 2021]. Disponible en: https://www.paho.org/es/temas/cancercervicouterino 
35. López L, Jerónimo J, Quispe R, Takahashi. Papanicolaou durante la menstruación: evaluación de muestras en cuatro hospitales de Lima. An Fac Med [Internet]. abril de 2011 [citado 15 de diciembre de 2020];72(2):125-30. Disponible en: http://www.scielo.org.pe/scielo.php?scrip $\mathrm{t}=$ sci_abstract\&pid=S1025-

55832011000200006\&lng=es\&nrm=iso\&t lng=es

36. Varela S. Citología Cervical. Rev Med Hondur 2005 [Internet]. 2005 [citado 5 de mayo de 2021];73. Disponible en: http://www.bvs.hn/RMH/pdf/2005/pdf/ Vol73-3-2005-7.pdf

37. Guglielmo ZD, Rodríguez A. Métodos utilizados en la identificación del virus de papiloma humano. An Sist Sanit Navar [Internet]. abril de 2010 [citado 2 de marzo de 2021];33(1):71-7. Disponible en: http://scielo.isciii.es/scielo.php?script=sci _abstract\&pid=S1137-

66272010000100008\&lng=es\&nrm=iso\&t lng=es

38. Ministerio-Salud-Neuquén_TumoresManual-recomendaciones-tamizaje-VPH2015.pdf [Internet]. [citado 27 de marzo de 2021]. Disponible en: https://www.saludneuquen.gob.ar/wpcontent/uploads/2020/09/MinisterioSalud-Neuqu\%C3\%A9n_Tumores-Manualrecomendaciones-tamizaje-VPH-2015.pdf

39. World Health Organization, World Health Organization, Reproductive Health and Research. Comprehensive cervical cancer control: a guide to essential practice. [Internet]. 2014 [citado 13 de mayo de 2020]. Disponible en: http://apps.who.int/iris/bitstream/10665 /144785/1/9789241548953_eng.pdf?ua= 1

40. Mateos ML, Chacón de Antonio J, Rodríguez-Domínguez M, Sanz I, Rubio MD. Evaluación de un sistema de PCR a tiempo real (cobas 4800) para la detección separada de los genotipos 16 y 18 y otros genotipos de alto riesgo del virus del papiloma humano en la prevención del cáncer cervical. Enfermedades Infecc Microbiol Clínica [Internet]. 1 de junio de 2011 [citado 27 de marzo de 2021];29(6):411-4. Disponible en: https://www.elsevier.es/es-revistaenfermedades-infecciosas-microbiologiaclinica-28-articulo-evaluacion-un-sistemapcr-tiempo-S0213005X11000279

41. Moreno RC, Ml ML. Diagnóstico microbiológico de la infección por el virus del papiloma humano. [Internet]. Sociedad Española de Enfermedades Infecciosas y Microbiología Clínica (SEIMC). 2016.; Disponible en: https://www.seimc.org/contenidos/docu mentoscientificos/procedimientosmicrobi ologia/seimcprocedimientomicrobiologia57.pdf

42. Herrera YA, Piña-Sánchez P. Historia de la evolución de las pruebas de tamizaje en el cáncer cervicouterino. Rev Med Inst Mex Seguro Soc [Internet]. 2015;8. Disponible en: https://www.medigraphic.com/pdfs/imss /im-2015/im156b.pdf

43. The cobas $®$ HPV Test [Internet]. [citado 5 de mayo de 2021]. Disponible en: https://diagnostics.roche.com/global/en/ products/params/cobas-hpv.html

44. Organización Panamericana de la Salud. Incorporación de la prueba del virus del papiloma humano en programas de prevención de cáncer cervicouterino. [Internet]. Incorporación de la prueba del virus del papiloma humano en programas de prevención de cáncer cervicouterino. Manual para gerentes de programas de salud. 2016 [citado 5 de mayo de 2021]. Disponible en: https://iris.paho.org /handle/10665.2/31223

45. Rojas R. Test cobas $® 4800$ HPV Respuestas precisas. Decisiones claras. [Internet]. 2011 [citado 6 de mayo de 2021]. Disponible en: http://revistabioreview.com/revistanota.php?nota $=817 \&$ revista $=12$

46. Calva-Espinosa DY, Campos-Romero A, Moreno-Camacho JL, Meza-Castro MC, Canizalez Román VA, Alcántar-Fernández J, 
et al. Comparación de plataformas automatizadas para la genotipificación del virus del papiloma humano. Ginecol Obstet México [Internet]. 2017 [citado 6 de mayo de 2021];85(9):569-77. Disponible en: http://www.scielo.org.mx/scielo.php?scri pt=sci_abstract $\&$ pid $=S 0300$ -

90412017000900569\&lng=es\&nrm=iso\&t lng=es

47. Ulloa GR. Captura Híbrida de ADN del Virus de Papiloma Humano en la Detección de Tipos de Alto Riesgo para el Cáncer de Cérvix Uterino (Revisión Bibliográfica). Rev MEDICA COSTA RICA Centroam [Internet]. 2008;LXV (585) 285290;2008:6. Disponible en: https://www.medigraphic.com/pdfs/rev medcoscen/rmc-2008/rmc084k.pdf

48. Tena D, Garrido N, Menéndez JM, Delgado JJ, Romanyk J, González M del R, et al. Utilidad de la detección del virus del papiloma humano de alto riesgo mediante Hybrid Capture II ${ }^{\circledR}$ en mujeres con citologías anormales del cuello uterino. Enfermedades Infecc Microbiol Clínica [Internet]. 1 de octubre de 2005 [citado 7 de mayo de 2021];23(8):474-8. Disponible en: https://www.elsevier.es/es-revistaenfermedades-infecciosas-microbiologiaclinica-28-articulo-utilidad-deteccion-delvirus-del-13078825

49. Almonte M. Actualización sobre la evidencia de las pruebas de VPH y los métodos de tratamiento de lesiones precancerosas. OPS/OMS | Organización Panamericana de la Salud [Internet]. 2018 [citado 5 de mayo de 2021]. Disponible en: https://webcache.googleusercontent.com/ search?q=cache:fwBTDdIVMQMJ:https:// www.paho.org/es/documentos/actualizac ion-sobre-evidencia-pruebas-vphmetodos-tratamiento-lesionesprecancerosas $+\& \mathrm{~cd}=1 \& \mathrm{hl}=\mathrm{es}-$ $419 \& \mathrm{ct}=\mathrm{clnk} \& \mathrm{gl}=\mathrm{ec}$

50. Lineros-Hurtado JA, Romero-Romero P, Salgado-Lerma YM, Wiesner-Ceballos C. Características operativas de técnicas moleculares empleadas para la detección del virus del papiloma humano en el proyecto ESTAMPA. Rev Colomb Cancerol [Internet]. 3 de julio de 2020 [citado 7 de mayo de 2021];24(3):135-40. Disponible en: https://www.revistacancercol.org /index.php/cancer/article/view/106

51. Medina ML, Medina MG, Merino LA. Valoración diagnóstica de técnicas moleculares para detección de infección bucal por virus del papiloma humano. Rev Costarr Salud Pública 2012 Vol $21 \mathrm{~N}^{\circ} 2$ [Internet]. 2012;21:7. Disponible en: https://www.scielo.sa.cr/pdf/rcsp/v21n2 /art13v21n2.pdf

52. Magûes M, Guillermo L. Genotipificación del virus del papiloma humano mediante secuenciamiento y PCR cuantitativa en tiempo real y detección de variantes intratípicas por análisis fitogenético [Internet] [Genotipificación del Virus del Papiloma Humano mediante secuenciamiento y PCR cuantitativa en tiempo real y detección de variantes intratípicas por análisis filogenético.]. [Guayaquil - Ecuador]: Escuala Superior Politecnica del Litorall; 2015 [citado 7 de mayo de 2021]. Disponible en: http://www.dspace.espol.edu.ec/handle/1 23456789/29767

53. Hesselink AT, Sahli R, Berkhof J, Snijders PJF, van der Salm ML, Agard D, et al. Clinical validation of Anyplex ${ }^{\mathrm{TM}}$ II HPV HR Detection according to the guidelines for HPV test requirements for cervical cancer screening. J Clin Virol [Internet]. 1 de marzo de 2016 [citado 7 de mayo de 2021];76:36-9. Disponible en: https://www.sciencedirect.com/science/a rticle/pii/S1386653216000111

54. Herrera YA, Piña-Sánchez P. Historia de la evolución de las pruebas de tamizaje en el cáncer cervicouterino. Rev Med Inst Mex Seguro Soc [Internet]. 2015;8. Disponible en: https://www.medigraphic.com/pdfs/imss /im-2015/im156b.pdf

55. Van Hamont $D$, van Ham MAPC, Bakkers JMJE, Massuger LFAG, Melchers WJG. Evaluation of the SPF10-INNO LiPA Human Papillomavirus (HPV) Genotyping 
Test and the Roche Linear Array HPV Genotyping Test. J Clin Microbiol [Internet]. septiembre de 2006 [citado 5 de mayo de 2021];44(9):3122-9. Disponible en: https://www.ncbi.nlm.nih.gov/pmc/ articles/PMC1594724/

56. Calderón JES, Campos AS. Eficacia de las pruebas diagnósticas del Cáncer Cervicouterino y Virus del Papiloma Humano. J Negat No Posit Results [Internet]. 10 de abril de 2019 [citado 5 de mayo de 2021];4(5):551-66. Disponible en: https://revistas.proeditio.com/jonnpr /article/view/2953
57. Guglielmo ZD, Rodríguez A. Métodos utilizados en la identificación del virus de papiloma humano. An Sist Sanit Navar [Internet]. abril de 2010 [citado 27 de marzo de 2021];33(1):71-7. Disponible en: http://scielo.isciii.es/scielo.php?script=sci _abstract\&pid=S1137-6627201000010 0008\&lng=es\&nrm=iso\&tlng=es

Conflicto de interese: Los autores declaran que no existe conflicto de intereses para la publicación del presente artículo.

Financiamiento: Autofinanciamiento

Agradecimiento: No declaran 